\title{
Patience, Persistence, and Welfare Costs of Incomplete Markets in Open Economies*
}

\author{
Jinill Kim, University of Virginia ${ }^{\dagger}$ \\ Sunghyun Henry Kim, Brandeis University \\ Andrew Levin, Federal Reserve Board ${ }^{\S}$
}

March 2001

- JEL Classification: F41, D52

${ }^{*}$ We appreciate comments and suggestions from Marianne Baxter, Hal Cole, Urban Jermann, Bob King, Robert Kollman, Stephanie Schmidt-Grohe, Chris Sims, Martin Uribe, Maria Vassalou, Paul Willen, and seminar participants at the Chicago Federal Reserve Bank, CEPR/LIFE/Weiss Center conference, Econometric Society World Congress, Federal Reserve Board, INSEAD, Korea Macro Workshop, Midwest Economic Association conference, Midwest Macroeconomics Conference, T2M conference, the University of Virginia, and the University of Pennsylvania. J. Kim's work on this project was supported by a Bankard grant from the University of Virginia.

$\dagger 114$ Rouss Hall, Department of Economics, University of Virginia, Charlottesville, VA 229044182. Tel: 804-924-7581, Fax: 804-982-2904, E-mail: jk9n@virginia.edu.

${ }^{\ddagger}$ Department of Economics MS 021, Brandeis University, Waltham, MA 02454. Tel: 781736-2268, Fax: 781-736-2263, E-mail: hkim@brandeis.edu.

${ }^{\S}$ Federal Reserve Board, Stop 22, 20th and C Streets, NW, Washington DC 20551. Tel: 202-452-3541, Fax: 202-736-5638, E-mail: andrew.levin@frb.gov. 


\begin{abstract}
In this paper, we investigate the welfare implications of alternative financial market structures in a two-country endowment economy model. In particular, we obtain an analytic expression for the expected lifetime utility of the representative household when sovereign bonds are the only internationally traded asset, and we compare this welfare level with that obtained under complete asset markets. The welfare cost of incomplete markets is negligible if agents are very patient and shocks are not very persistent, but this cost is dramatically larger if agents are relatively impatient and shocks are highly persistent. For realistic cases in which agents are very patient and shocks are highly persistent (that is, the discount factor and the first-order autocorrelation are both near unity), the welfare cost of incomplete markets is highly sensitive to the specific values of these parameters. Finally, using a non-linear solution algorithm, we confirm that a two-country production economy with endogenous labor supply has qualitatively similar welfare properties.
\end{abstract}




\section{Introduction}

In recent years, numerical methods have been used to analyze a wide variety of open-economy dynamic general equilibrium models with incomplete asset markets. ${ }^{1}$ In particular, Baxter and Crucini (1995) showed that the degree of persistence and spillovers of the exogenous shocks plays a critical role in determining the extent to which the behavior of the incomplete-markets economy diverges from that of the economy with complete asset markets. ${ }^{2}$ Tesar (1995) obtained quantitative results regarding the welfare costs of financial market incompleteness under various model specifications. ${ }^{3}$ However, there has been a relative scarcity of analytical results to elucidate these results and to clarify the implications of the key structural parameters. ${ }^{4}$

In this paper, we use analytical methods to determine the welfare implications of a two-country endowment economy, in which each country has an infinitely-lived representative agent, and for which sovereign bonds are the only internationallytraded asset. For simplicity, we also assume that the two countries are completely symmetric, with no outstanding debt at the beginning of the initial period, and that each country is subject to a single endowment shock that decays at an exponential rate. Under these assumptions, we can obtain the exact non-linear rational expectations solution for the dynamic behavior of the economy; that is, the entire path of each country's consumption can be expressed in terms of the exogenous endowment process. ${ }^{5}$ Then we proceed to derive an analytic expression

\footnotetext{
${ }^{1}$ For example, two-country models with incomplete markets have been analyzed by Baxter and Crucini (1995), Kollmann (1996, 1998), and Mendoza and Tesar (1998), while small open economy models have been considered by Mendoza (1995) and Mendoza and Uribe (1999). Analysis of two-country models has also proceeded under the assumption of complete international asset markets; cf. Backus et al. (1992), Baxter and Crucini (1993). Further discussion may be found in Baxter (1997).

${ }^{2}$ Glick and Rogoff (1995) and Obstfeld and Rogoff (1996) have analyzed the implications of the degree of persistence of the exogenous shocks. These issues have also been studied extensively in a partial-equilibrium context, e.g., the large literature on the permanent-income hypothesis, starting with Friedman (1957).

${ }^{3}$ Numerical results on welfare gains of incomplete markets have been obtained by Mendoza (1995), Tesar (1995), Kim (1997), and Kubler and Schmedders (2000). A relatively large literature has considered the welfare gains of complete asset markets over autarky using both analytical and numerical methods; cf. the summary and analysis in van Wincoop (1999). Lewis (2000) provides a broad survey of the literature on welfare gains from international risk-sharing.

${ }^{4}$ Cole (1988) obtained an exact analytic solution for the behavior of a two-period incomplete market model. Several other recent papers will be discussed below.

${ }^{5}$ We do not adopt the loglinear approximation method followed in the literature. As shown
} 
for the expected lifetime utility of the representative agent (using a second-order Taylor approximation around the steady-state growth path of the endowments), and we compare this welfare level with that obtained under complete markets and under autarky. ${ }^{6}$

We find that the welfare cost of incomplete markets increases linearly with the degree of relative risk aversion and with the variance of the country-specific component of the endowment shocks, whereas this welfare cost depends nonlinearly on the persistence and spillovers of the endowment shocks and on the growthadjusted discount factor (which is a simple function of the discount factor, the growth rate, and the intertemporal elasticity of substitution). In addition to facilitating greater intuition about the effects of patience and persistence, these analytic results permit us to identify potentially realistic cases in which the welfare of the incomplete-markets economy is quite sensitive to small changes in the structural parameters. Finally, we use the stacked Newton algorithm to analyze a two-country production economy with endogenous labor supply, and we confirm that the welfare implications are qualitatively similar to those of the endowment economy model.

It is interesting to compare our results with those obtained by Devereux and Saito (1997), who analyzed an open-economy "AK model" in which each country's output is a linear function of its capital stock (which does not depreciate). Thus, an idiosyncratic productivity shock has a permanent effect on the capital stock and hence the level of output. In this setting, each country's risk-free interest rate is time-invariant under autarky, and no international risk-sharing occurs when countries are symmetric and sovereign bonds are the only internationally traded asset. These findings are completely consistent with the results that we obtain for the special case of permanent shocks.

Our analysis is also complementary to that of Davis et al. (2000), who used the theoretical framework of Willen (1999) to quantify the potential welfare gains from more complete international asset markets. These authors utilize a model in which the global endowment is deterministic while each individual country's

in Kim and Kim (1999), this method can severely distort the welfare implications; for example, in certain cases this method yields the nonsensical result that social welfare is lower under complete markets than under autarky.

${ }^{6}$ It should be noted that this expression for social welfare is not obtained by taking a loglinear approximation with respect to the initial levels of consumption and bond holdings. Hence, our welfare approximation becomes arbitrarily close to the exact solution as the variance of the exogenous shocks becomes arbitrarily small. (See the discussion in Woodford 1999 and Sims 2000.) 
endowment follows a stochastic process. This framework permits the analysis of alternative degrees of persistence for each country's endowment shocks, but implies a constant world risk-free real interest rate. In contrast, our model allows for a stochastic world endowment and an endogenous risk-free real interest rate, and hence is suitable for analyzing the welfare costs of incomplete markets for relatively large economies. ${ }^{7}$

Finally, while our analysis is mainly intended as a contribution to the international finance literature, it should be noted that our paper is also closely related to the risk-sharing literature in general equilibrium microeconomics. In particular, Levine and Zame (1999) obtained necessary and sufficient conditions under which the welfare cost of incomplete asset markets is arbitrarily small. Our model not only illustrates these conditions but also sheds light on the properties of the incomplete-markets economy when its behavior deviates substantially from that obtained under complete markets.

The remainder of this paper proceeds as follows. Section 2 presents analytical results for the two-country endowment economy model. Section 3 reports numerical results for a two-country production economy model with endogenous labor supply. Finally, Section 4 highlights our conclusions and suggests some topics for future research. The appendix provides details of the analytical derivations in Section 2 and the numerical solution algorithm in Section 3.

\section{The Endowment Economy}

In this section, we analyze a two-country endowment economy in which risk-free discount bonds are the only internationally traded asset. The two countries are assumed to be identical, with a zero net asset position at the beginning of the initial period, $t=0$. The representative infinitely-lived household in each country chooses its consumption and bond holdings in order to maximize its present discounted utility, subject to the risk-free interest rate and to its exogenously given endowment sequence. Each country's initial endowment is subject to a random disturbance, which may have a persistent impact on its subsequent endowments and may also have spillover effects (with a one-period lag) on the other country's endowment sequence.

\footnotetext{
${ }^{7}$ The models of Willen (1999) and Davis et al. (2000) utilize an exponential utility specification and Gaussian endowment shocks; this approach is quite common in microeconomics, whereas our specification of CES utility and log-normal shocks is fairly standard in macroeconomics and international finance.
} 


\subsection{The Model}

The representative household in the home country solves the following problem:

$$
\max \sum_{t=0}^{\infty} \beta^{t} U\left(C_{t}\right), \text { where } U(C)=\frac{C^{1-\gamma}-1}{1-\gamma},
$$

subject to

$$
C_{t}+B_{t}=R_{t-1} B_{t-1}+Y_{t} \text { for every } t=0,1,2, \ldots
$$

where $C_{t}$ indicates home-country consumption; $Y_{t}$ indicates the exogenous homecountry endowment level; $B_{t}$ denotes the quantity of risk-free discount bonds held at the end of period $t$ (where a negative value of $B_{t}$ corresponds to net sales); and $R_{t}$ indicates the gross risk-free interest rate. The household utility function exhibits constant relative risk aversion $\gamma$ and constant intertemporal elasticity of substitution $1 / \gamma$. The conditional expectations operator is omitted from equation (2.1) because we assume that no additional shocks occur after period $t=0$. The representative household in the foreign country has identical preferences, and chooses a sequence of consumption levels $C_{t}^{*}$ and bond holdings $B_{t}^{*}$ to maximize its lifetime utility, given the gross interest rate $R_{t}$ and its exogenous endowment sequence $Y_{t}^{*}$.

We assume that the initial endowments $Y_{0}$ and $Y_{0}^{*}$ are drawn from a bivariate log-normal distribution. In particular, $\log Y_{0}$ and $\log Y_{0}^{*}$ each have mean $-\sigma^{2} / 2$ and variance $\sigma^{2}$, and the two series have correlation $\psi$. This specification enables us to consider mean-preserving spreads; that is, $\mathrm{E}\left(Y_{0}\right)=\mathrm{E}\left(Y_{0}^{*}\right)=\bar{Y}_{0}=1$ regardless of the specific value of $\sigma^{2}$.

In subsequent periods, each country's endowment has a deterministic component which grows at a constant rate: $Y_{t}=\mu^{t} y_{t}$ and $Y_{t}^{*}=\mu^{t} y_{t}^{*}$ for $t=1,2, \ldots$. The detrended endowments $y_{t}$ and $y_{t}^{*}$ are determined by the following bivariate Markov process:

$$
\left[\begin{array}{l}
\log y_{t} \\
\log y_{t}^{*}
\end{array}\right]=\left[\begin{array}{cc}
\rho & \theta \\
\theta & \rho
\end{array}\right]\left[\begin{array}{l}
\log y_{t-1} \\
\log y_{t-1}^{*}
\end{array}\right] \text { for } t=1,2, \ldots,
$$

where we refer to $\rho$ as the persistence parameter and $\theta$ as the spillover parameter. Dynamic stability requires that $|\rho+\theta|<1$ and $|\rho-\theta|<1$.

For notational simplicity in the following analysis, it is convenient to define $A_{t} \equiv R_{t-1} B_{t-1}$, where $A_{t}$ is naturally interpreted as the beginning-of-period asset position. Thus, the asset transition equation (2.2) can be equivalently expressed as

$$
A_{t+1}=R_{t}\left(A_{t}+Y_{t}-C_{t}\right) \text {. }
$$


We assume henceforth that no bonds are outstanding at the beginning of the initial period; that is, $A_{0}=0$. Thus, imposing the usual transversality condition on bond holdings, the household faces the following intertemporal budget constraint in period $t=0$ :

$$
C_{0}+\sum_{t=1}^{\infty}\left(\prod_{s=0}^{t-1} R_{s}\right)^{-1} C_{t}=Y_{0}+\sum_{t=1}^{\infty}\left(\prod_{s=0}^{t-1} R_{s}\right)^{-1} Y_{t}
$$

Then the solution to the household's maximization problem is given by equation (2.5) together with the following sequence of first-order conditions:

$$
C_{t}^{-\gamma}=\beta R_{t} C_{t+1}^{-\gamma} \text { for every } t=0,1,2, \ldots
$$

The solution to the foreign household's maximization problem is given by expressions parallel to equations (2.5) and (2.6), involving $C_{t}^{*}$ and $Y_{t}^{*}$ instead of $C_{t}$ and $Y_{t}$. Finally, in general equilibrium, the following bond market clearing conditions must be met in every period:

$$
A_{t}+A_{t}^{*}=0 \text { for every } t=0,1,2, \ldots
$$

It should be noted that these market-clearing conditions (combined with the home and foreign asset transition equations) are equivalent to the following sequence of global resource constraints:

$$
C_{t}+C_{t}^{*}=Y_{t}+Y_{t}^{*} \text { for every } t=0,1,2, \ldots
$$

\subsection{The Analytic Solution}

Since no additional shocks occur after period $t=0$, the home and foreign consumption Euler equations can be expressed as follows:

$$
\begin{aligned}
& C_{t+1}=\beta^{1 / \gamma} R_{t}^{1 / \gamma} C_{t} \\
& C_{t+1}^{*}=\beta^{1 / \gamma} R_{t}^{1 / \gamma} C_{t}^{*}
\end{aligned} \text { for all } t=0,1,2, \ldots
$$

By adding these two equations together, substituting the global resource constraint (2.8), and dividing by the deterministic time trend $\mu^{t}$, we obtain the following expression for the gross interest rate $R_{t}$ :

$$
R_{t}=\frac{\mu^{\gamma}}{\beta}\left(\frac{Y_{t+1}+Y_{t+1}^{*}}{Y_{t}+Y_{t}^{*}}\right)^{\gamma}
$$


It should be noted that exactly the same expression for $R_{t}$ is obtained in the case of complete contingent-claims markets, for which $C_{t}=C_{t}^{*}=\frac{1}{2}\left(Y_{t}+Y_{t}^{*}\right)$ in every period $t$. In other words, when shocks only occur in the initial period, complete consumption insurance leads to an international transfer of wealth at time $t=0$, but has no effect on the expected slope of each country's consumption profile. Thus, in this environment, the entire path of $R_{t}$ is the same regardless of whether agents have access to a complete set of contingent claims or are limited to risk-free discount bonds. Of course, this property of $R_{t}$ will not necessarily hold exactly under more general assumptions. Nevertheless, it is interesting to note that Baxter and Crucini (1995) and others have analyzed two-country production economy models with endogenous capital and labor, and have found that the first-order behavior of interest rates is virtually identical under complete and incomplete markets.

In the absence of any shocks (that is, $\sigma^{2}=0$ ), the endowments $Y_{t}=Y_{t}^{*}=\mu^{t}$ for every period $t$; hence, it is evident from equation (2.10) that the steady-state gross interest rate is $\left(\beta^{-1} \mu^{\gamma}\right)$. Thus, as in the previous literature (e.g., Baxter and Crucini 1995), it is useful to define the growth-adjusted gross interest rate $\tilde{R}_{t}=R_{t} / \mu$ and the growth-adjusted discount factor $\tilde{\beta}=\beta \mu^{1-\gamma} ;$ it should be noted that the condition $\tilde{\beta}<1$ is required to ensure that lifetime utility is well-defined and that $\tilde{\beta}$ equals the inverse of the steady-state value of $\tilde{R}_{t}{ }^{8}$ Furthermore, if the growth rate is positive $(\mu>1)$, then the steady-state real interest rate is higher than in the absence of growth; in other words, given household preferences for smooth consumption, the equilibrium steady-state real interest rate must be relatively high when consumption growth is expected to be positive.

Using these definitions, equation (2.10) can be rewritten as

$$
\tilde{R}_{t}=\tilde{\beta}^{-1}\left(\frac{y_{t+1}+y_{t+1}^{*}}{y_{t}+y_{t}^{*}}\right)^{\gamma} .
$$

By substituting equation (2.11) into the home-country household's intertemporal budget constraint (2.5), we obtain the following solution for the entire path of its consumption as a function of the exogenous sequences of home and foreign

\footnotetext{
${ }^{8}$ The same approach is followed in Barro and Sala-i-Martin (1995) and Romer (1996).
} 
endowments:

$$
\begin{aligned}
C_{0} & =\frac{Y_{0}+\left(\frac{Y_{0}+Y_{0}^{*}}{2}\right)^{\gamma} \sum_{t=1}^{\infty} \tilde{\beta}^{t}\left(\frac{y_{t}+y_{t}^{*}}{2}\right)^{-\gamma} y_{t}}{1+\left(\frac{Y_{0}+Y_{0}^{*}}{2}\right)^{\gamma-1} \sum_{t=1}^{\infty} \tilde{\beta}^{t}\left(\frac{y_{t}+y_{t}^{*}}{2}\right)^{1-\gamma}} \\
C_{t} & =\mu\left(\frac{y_{t}+y_{t}^{*}}{y_{t-1}+y_{t-1}^{*}}\right) C_{t-1} \text { for all } t=1,2, \ldots
\end{aligned}
$$

The foreign country's consumption path is symmetric to equations (2.12) and (2.13).

Finally, we note that under autarky, each country's representative household simply consumes its own endowment; that is, $C_{t}=Y_{t}$ for every period $t$.

\subsection{Welfare}

To evaluate the welfare implications of alternative financial market structures, it is natural to consider the expected lifetime utility of the representative household at the beginning of period $t=0$, prior to observing the specific values of the endowment shocks. ${ }^{9}$ Given the symmetry between the home and foreign countries, expected lifetime utility is identical for households in both countries. Since an exact analytic solution is not tractable, we derive the second-order Taylor approximation of lifetime utility with respect to the deviations of the endowments from their steady-state growth path, and then take the mathematical expectation with respect to the initial endowment shocks. (A first-order approximation is not sufficient to reveal the welfare effects of alternative financial market structures.) Finally, as in Lucas (1987), we use compensating variations to express deviations of expected lifetime utility in terms of the corresponding deviation in certainty-equivalent consumption (relative to steady state). In this case, since we are considering a one-time exogenous shock rather than a stationary sequence of shocks, it is appropriate to express these welfare effects in terms of a shift in certainty-equivalent consumption in the initial period. ${ }^{10}$

\footnotetext{
${ }^{9}$ That is, we analyze the household's expected lifetime utility conditional on its information set in period $t=-1$.

${ }^{10}$ Of course, one can multiply the result by $(1-\tilde{\beta})$ to express welfare in terms of a permanent shift in certainty-equivalent consumption (as in Lucas 1987). However, using that measure of welfare, the gains of eliminating a one-time shock become arbitrarily small as $\tilde{\beta}$ approaches unity, regardless of the structure of financial markets.
} 
Using this approach, we obtain the following expression for the welfare cost of incomplete markets compared with complete international risk-sharing:

$$
W^{i n c}-W^{c o m p}=\frac{-\gamma(1-\tilde{\beta})(1-\psi) \sigma^{2}}{4[1-\tilde{\beta}(\rho-\theta)]^{2}} .
$$

Under the stability conditions $0<\tilde{\beta}<1$ and $|\rho-\theta|<1$, it is evident that $W^{i n c}-W^{c o m p} \leq 0$; that is, the first fundamental welfare theorem is satisfied. As expected, there are no gains from international risk-sharing when households are risk-neutral $(\gamma=0)$ or when the endowment shocks are perfectly correlated across the two countries $(\psi=1)$. More generally, the welfare cost of incomplete markets increases linearly with the degree of relative risk aversion $(\gamma)$ and with the variance of the country-specific component of the endowment shocks $\left((1-\psi) \sigma^{2}\right)$. In contrast, the growth-adjusted discount factor $\tilde{\beta}$ and the endowment shock parameters $\rho$ and $\theta$ can have highly nonlinear effects on welfare. As noted above, $\tilde{\beta}$ is inversely related to the steady-state real interest rate, while the deviation $(\rho-\theta)$ indicates the extent to which a given shock has persistent effects that do not spill over to the other country.

The autarkic economy also provides a natural benchmark for evaluating the welfare associated with alternative financial market structures. In particular, we find that

$$
W^{\text {inc }}-W^{\text {aut }}=\lambda^{c}\left(W^{\text {comp }}-W^{\text {aut }}\right)
$$

where

$$
\lambda^{c}=\tilde{\beta}\left[\frac{1-(\rho-\theta)}{1-\tilde{\beta}(\rho-\theta)}\right]^{2} .
$$

and

$$
W^{\text {comp }}-W^{\text {aut }}=\frac{\gamma(1-\psi) \sigma^{2}}{4\left[1-\tilde{\beta}(\rho-\theta)^{2}\right]} .
$$

Under the stability conditions noted above, it is evident that $0<\lambda^{c}<1$ and that $W^{\text {comp }}-W^{\text {aut }} \geq W^{\text {inc }}-W^{\text {aut }} \geq 0$, consistent with the first fundamental welfare theorem.

The index $\lambda^{c}$ provides a useful measure of the relative welfare of the incompletemarkets economy: that is, $W^{\text {inc }} \rightarrow W^{\text {aut }}$ as $\lambda^{c} \rightarrow 0$, and $W^{\text {inc }} \rightarrow W^{\text {comp }}$ as $\lambda^{c} \rightarrow 1$. This index only involves the growth-adjusted discount factor $\tilde{\beta}$ and the deviation $(\rho-\theta)$, that is, the degree to which a given shock has persistent effects 
that do not spill over to the other country. It should be noted that $\lambda^{c}$ depends indirectly on the discount factor $\beta$, the growth rate of the economy $(\mu-1)$, and the intertemporal elasticity of substitution $(1 / \gamma)$, because the growth-adjusted discount factor $\tilde{\beta}$ is defined in terms of these parameters.

It is interesting to evaluate the welfare implications of these expressions for the postwar U.S. and EU economies, under two alternative assumptions about the persistence of the exogenous shocks. In our baseline calibration, we set the structural parameters $\beta=0.99$ and $\gamma=2$, and we assume that output follows a stationary process with parameters $\rho=0.906, \theta=0.088, \psi=0.258, \mu=1.004$, and $\sigma=0.00852$ (cf. Backus et al. 1992; Baxter and Crucini 1995). Under the baseline calibration, incomplete markets perform nearly as well as complete markets: the relative welfare index $\lambda^{c}=0.87$, and the welfare cost of incomplete markets $\left(W^{\text {inc }}-W^{\text {comp }}\right)$ is only about 0.001 percent of steady-state consumption in the initial period, $\bar{Y}_{0}$. By comparison, the welfare gain of complete markets over autarky $\left(W^{\text {comp }}-W^{\text {aut }}\right)$ is equal to 0.008 percent of $\bar{Y}_{0}$, and is about half as large as the welfare gain obtained by eliminating all aggregate consumption volatility (cf. Lucas 1987).

Under the alternative calibration, each country's productivity is assumed to follow a random walk with no spillovers; that is, $\rho=1$ and $\theta=0$, while the remaining parameters have the same values as in the baseline calibration. In this case, the initial shock has a permanent effect on the level of output, so that bonds cannot facilitate international risk-sharing through the intertemporal smoothing motive. Thus, the economy with incomplete markets yields the same welfare as the autarkic economy (that is, $\lambda^{c}=0$ ), while the welfare difference between complete and incomplete markets $\left(W^{i n c}-W^{\text {comp }}\right)$ is equal to 0.19 percent of $\bar{Y}_{0}$; that is, the welfare cost of incomplete markets is nearly 200 times as large as under the baseline calibration.

\subsection{Patience}

Using the baseline parameter calibration indicated above, Figure 1 shows how $W^{\text {comp }}-W^{\text {aut }}$ and $W^{\text {inc }}-W^{\text {aut }}$ vary as a function of the growth-adjusted discount factor $\tilde{\beta}$. In particular, the welfare of the incomplete-market economy approaches that of autarky when the value of $\tilde{\beta}$ is relatively small, and approaches that of complete markets when the value of $\tilde{\beta}$ is relatively close to unity.

To gain further intuition about these results, it is useful to consider the special case in which the endowment shocks are purely transitory with no spillovers 
(that is, $\rho=\theta=0$ ). Under either autarky or complete markets, the economy immediately returns to steady state after the initial period; thus, the welfare gain $W^{\text {comp }}-W^{\text {aut }}$ does not depend on the value of $\tilde{\beta}$ (cf. equation 2.17). In contrast, under incomplete markets, the country with a relatively low endowment in the initial period borrows to enhance its consumption in the initial period, and then pays a stream of annuities on its debt in all subsequent periods. Since $\tilde{\beta}$ determines the steady-state value of the growth-adjusted gross interest rate $\tilde{R}_{t}$ (that is, $\bar{R} / \mu=\tilde{\beta}^{-1}$ ), it is not surprising that the welfare level of the incomplete-markets economy does depend on $\tilde{\beta}$. In particular, we find that

$$
W^{i n c}-W^{c o m p}=-\frac{1}{4} \gamma(1-\tilde{\beta})(1-\psi) \sigma^{2} .
$$

Thus, the welfare cost of incomplete markets declines monotonically with the growth-adjusted discount factor $\tilde{\beta}$. Furthermore, using equation (2.16), we see that the relative welfare index $\lambda^{c}$ is simply the growth-adjusted discount factor $\tilde{\beta}$ in this special case.

These results imply that when the growth-adjusted discount factor $\tilde{\beta}$ is very close to unity (or equivalently, as the growth-adjusted steady-state interest rate $\bar{R} / \mu$ is only slightly greater than unity), the behavior of the incomplete-markets economy will be very similar to that of the complete-markets economy. That is, to the extent that future consumption has a relatively high weight in lifetime utility, complete risk-sharing can be closely approximated even when risk-free bonds are the only internationally-traded asset. On the other hand, if lifetime utility is relatively insensitive to future consumption levels (that is, the growth-adjusted discount factor is near zero and the steady-state real interest rate is very high), then the behavior of the incomplete-markets economy will be similar to that of the autarkic economy.

For the infinite-horizon endowment economy, the results are not well-defined when $\tilde{\beta}$ is exactly equal to unity. Thus, to obtain further intuition about this limiting case, we briefly consider an alternative economy in which each household has a finite horizon of $J$ periods; for simplicity, we assume that the utility function has a logarithmic form (that is, $\gamma=1$ ). In this case, we find that the relative welfare index $\lambda^{c}$ is given by

$$
\lambda^{c}=\tilde{\beta} \frac{\left(1-\tilde{\beta}^{J+1}\right)}{\left(1-\tilde{\beta}^{J+2}\right)} .
$$


By L'Hôpital's rule, $\lambda^{c}$ approaches $\frac{J+1}{J+2}$ as $\tilde{\beta}$ approaches unity. Thus, the welfare cost of incomplete markets does not vanish unless the growth-adjusted discount factor is arbitrarily close to unity and the time horizon is arbitrarily large (cf. Levine and Zame 1999).

\subsection{Persistence and Spillovers}

Using our baseline parameter calibration, Figure 2 shows how $W^{\text {comp }}-W^{\text {aut }}$ and $W^{i n c}-W^{\text {aut }}$ vary as a function of $(\rho-\theta)$. It is evident that the welfare of the incomplete-market economy approaches that of complete markets when the value of $(\rho-\theta)$ is relatively small, and approaches that of autarky when the value of $(\rho-\theta)$ is close to unity. To gain further intuition about these results, it is useful to consider the special case in which the endowment shocks have no spillover effects (that is, $\theta=0$ ). From equation (2.16), the relative welfare index $\lambda^{c}$ is given by:

$$
\lambda^{c}=\tilde{\beta}\left[\frac{1-\rho}{1-\tilde{\beta} \rho}\right]^{2}
$$

Using formula (2.20), Figure 3 depicts the relative welfare index $\lambda^{c}$ as a function of the persistence parameter $\rho$ for specified values of $\tilde{\beta}$. This figure highlights the results shown in Figure 2: as $\rho$ approaches unity and hence the endowment shocks become permanent, the relative welfare index $\lambda^{c}$ approaches zero; that is, the welfare under incomplete markets approaches that of autarky. Intuitively speaking, the domestic country will not use discount bonds to smooth consumption when endowment shocks are permanent, since the endowment stream is already smooth. On the other hand, when shocks are relatively transitory (that is, $\rho$ is relatively small compared with $\tilde{\beta}$ ), the welfare cost of incomplete markets is very small. Nevertheless, as long as $\tilde{\beta}$ is strictly less than unity, the welfare of the incomplete-markets economy will be strictly less than that of the completemarkets economy. Finally, when both $\rho$ and $\tilde{\beta}$ are close to unity (as in many empirical applications), Figures 2 and 3 show that the behavior of the incompletemarkets economy is very sensitive to the exact values of these parameters. ${ }^{11}$

\footnotetext{
${ }^{11}$ In formal terms, the relative weight $\lambda^{c}$ is not a continuous function of $\rho$ and $\tilde{\beta}$ at the point $\rho=\tilde{\beta}=1$. However, if the time horizon is finite, the function is continuous and the welfare under incomplete markets is identical to that of autarky when $\rho=\tilde{\beta}=1$. Using numerical methods, Kubler and Schmedders (2000) also emphasize that the implications of incomplete markets are highly sensitive to the choice of $\beta$ and $\rho$ when both parameters are close to unity.
} 
From equation (2.14), it is evident that the welfare cost of incomplete markets is decreasing in the spillover parameter $\theta$, because the two countries experience more similar wealth effects when the impact of a given shock "spills over" to the other country. Thus, for any given value of the persistence parameter $\rho$, the behavior of the incomplete-markets economy is more similar to that of the complete-markets economy when the spillover parameter $\theta$ is relatively large. More specifically, it is useful to consider the eigenvalue decomposition of the bivariate autoregressive coefficient matrix defined in equation (2.3):

$$
\left[\begin{array}{c}
\left(\frac{\log y_{t}+\log y_{t}^{*}}{2}\right) \\
\log y_{t}-\left(\frac{\log y_{t}+\log y_{t}^{*}}{2}\right)
\end{array}\right]=\left[\begin{array}{cc}
(\rho+\theta) & 0 \\
0 & (\rho-\theta)
\end{array}\right]\left[\begin{array}{c}
\left(\frac{\log y_{t-1}+\log y_{t-1}^{*}}{2}\right) \\
\log y_{t-1}-\left(\frac{\log y_{t-1}+\log y_{t-1}^{*}}{2}\right)
\end{array}\right] .
$$

Thus, the endowment shock process can be decomposed into two mutually orthogonal components. The first component is a global output shock with firstorder autocorrelation $(\rho+\theta)$, while the second component is an idiosyncratic shock with first-order autocorrelation $(\rho-\theta)$. Of course, welfare gains from international risk-sharing can only occur with respect to the idiosyncratic component.

This analysis helps provide some additional insights regarding the results obtained by Baxter and Crucini (1995), who used numerical methods to analyze the dynamic behavior of a two-country production economy model with endogenous capital and labor supply. Baxter and Crucini found very similar behavior of the incomplete-markets and complete-markets economies when total factor productivity shocks have moderately persistent effects with cross-country spillovers (namely, the baseline calibration in which $\rho=0.906$ and $\theta=0.088$ ), whereas the two economies behaved very differently in the case of permanent productivity shocks (that is, $\rho=1$ and $\theta=0$ ). Our analysis is completely consistent with these results: in the first case, the growth-adjusted discount factor $\tilde{\beta}$ is very close to unity, while $(\rho-\theta)$ is substantially less than unity, so we would expect the behavior of the incomplete-markets economy to approach that of complete markets. In contrast, when $\rho=1$, we would expect the incomplete-markets economy to behave very differently from the complete-markets economy (although its behavior will not be identical to that of autarky in a model with endogenous capital accumulation).

Finally, as noted above, the specific value of $\psi$ affects the level of welfare gains from international risk-sharing, which depend on the extent to which the two countries tend to face different shocks. However, it should be noted that the index $\lambda^{c}$ is invariant to the value of $\psi$; that is, the relative welfare of incomplete markets 
is not affected by the degree of contemporaneous correlation of the endowment shocks.

\section{Production Economy with Labor}

This section extends the endowment economy model to the production economy with endogenous labor supply. However, the analytical solution is not available without linearizing the model and linearization has potentially crucial problems in accuracy. Therefore, we solve the nonlinear model by using the stacked Newton algorithm and perform numerical analysis to evaluate the welfare implications of incomplete markets.

\subsection{The Model and Solution Algorithm}

Each country faces the following maximization problem with a separable utility function:

$$
\max \sum_{t=0}^{\infty} \beta^{t} U\left(C_{t}, L_{t}\right), \text { where } U(C, L)=\frac{C^{1-\gamma}-1}{1-\gamma}+\nu_{0} \nu\left(1-L^{\frac{1}{\nu}}\right),
$$

subject to

$$
\begin{aligned}
C_{t}+B_{t} & =R_{t-1} B_{t-1}+Y_{t} \\
Y_{t} & =X_{t} L_{t}^{1-\alpha}, \text { for all } t
\end{aligned}
$$

where $X_{t}$ is productivity, $L_{t}$ is the amount of labor. The labor production technology can be nonlinear with a nonzero $\alpha$. The parameter $\nu$, taking a value between 0 and 1, represents how elastic the labor supply is. The elasticity of labor supply is $\nu /(1-\nu)$, which is increasing in $\nu$ and takes a value between 0 and $\infty$. We solve the model assuming $\nu_{0}=1-\alpha$ for notational simplicity.

We solve the model using the stacked Newton algorithm, a numerically efficient algorithm for solving non-linear equations. ${ }^{12}$ Compared with log-linearization, the stacked Newton algorithm is computationally more intensive, but may provide a substantially more accurate solution if the non-linear system is relatively far from being log-linear, or if the steady state exhibits large shifts in response to exogenous

\footnotetext{
${ }^{12}$ We use the stacked-Newton algorithm in Troll 1.03 because of its computational efficiency, but one could also use an alternative algorithm such as Gauss-Seidel algorithm used in Fair and Taylor (1983).
} 
shocks of reasonable magnitude. The algorithm works directly with the non-linear first-order conditions and resource constraints. In particular, we consider the set of equations that describe the entire path of all model variables from the current period through some finite horizon in the future, at which point the system is assumed to have reached its new steady state. Thus, these terminal conditions replace the corresponding Euler equations in the horizon period. Finally, we confirm that the solution is invariant to using a longer horizon.

\subsection{Welfare Implications}

To analyze the welfare implications of alternative financial market structures, we consider a single shock to the home country's total factor productivity, leaving the foreign country's total factor productivity unchanged. For simplicity, we abstract from growth, so that steady-state productivity $\bar{X}_{t}=1$ for every period $t$. The initial productivity disturbance only takes one of two values with equal probability, that is, $\log \left(X_{0}\right)= \pm 0.03-0.00036$. Thus, initial total factor productivity shifts by roughly 3 percent, with a small adjustment to achieve a mean-preserving spread. The productivity disturbance decays at the rate $\rho$; that is, $\log \left(X_{t}\right)=\rho \log \left(X_{t-1}\right)$ for every period $t>0$. We assume that $\theta=0$ for simplicity. For the baseline calibration, we set $\alpha=0.33, \tilde{\beta}=\beta=0.986$, $\gamma=2$, and $\nu=0.5$. Using the numerical methods outlined above, we compute the expected lifetime utility of the representative household in each country at the beginning of period $t=0$, prior to observing the specific value of the total factor productivity shock. Finally, we express world welfare (that is, the average of expected lifetime utility across the two countries) in terms of the certaintyequivalent shift in consumption in the initial period, holding leisure at its steadystate value.

Using the baseline parameter calibration, Figure 4 shows how $W^{\text {comp }}-W^{\text {aut }}$ and $W^{\text {inc }}-W^{\text {aut }}$ vary as a function of the persistence parameter $\rho$. As in the endowment economy model considered in Section 2, the welfare of the incompletemarket economy approaches that of complete markets when shocks have relatively low persistence, and approaches that of autarky as shocks become highly persistent.

For alternative values of $\gamma, \nu$, and $\rho$, Table 1 presents the value of $\lambda^{c}$, the relative welfare loss of the incomplete-market economy. In particular, we consider $\gamma \in\{1,2\} ; \nu \in\{0,0.5,0.9\}$; and $\rho \in\{0,0.9,0.95,1.0\}$. In all cases, these results confirm the qualitative properties obtained in Section 2; that is, the welfare under 
incomplete markets is identical to that of autarky when $\rho=1$, and approaches that of complete markets when $\rho$ is substantially smaller than $\beta$. It is also interesting to note that an increase in the degree of relative risk aversion, $\gamma$ (or equivalently, a reduction in the intertemporal elasticity of consumption) has negligible impact on the relative welfare loss of the incomplete-market economy. The welfare results are also quite insensitive to the specific value of $\nu$, that is, the intertemporal elasticity of labor supply.

Table 1: Relative Welfare Index of Incomplete Markets $\left(\lambda^{c}\right)$ (Production Economy with Endogenous Labor Supply)

\begin{tabular}{|c|c|c|c|c|}
\hline \multicolumn{5}{|c|}{$\gamma=1$} \\
\hline$\rho$ & 0 & 0.9 & 0.95 & 1 \\
\hline \hline$\nu=0.0$ & 0.98600 & 0.77763 & 0.61508 & 0 \\
\hline$\nu=0.5$ & 0.98600 & 0.77762 & 0.61503 & 0 \\
\hline$\nu=0.9$ & 0.98600 & 0.77759 & 0.61493 & 0 \\
\hline \hline \multicolumn{5}{|c|}{$\gamma=2$} \\
\hline$\rho$ & 0 & 0.9 & 0.95 & 1 \\
\hline \hline$\nu=0.0$ & 0.98599 & 0.77745 & 0.61468 & 0 \\
\hline$\nu=0.5$ & 0.98599 & 0.77742 & 0.61457 & 0 \\
\hline$\nu=0.9$ & 0.98600 & 0.77734 & 0.61432 & 0 \\
\hline
\end{tabular}




\section{Conclusion}

In this paper, we have investigated average world welfare in open economies with three alternative financial market structures: autarky; complete markets; and incomplete markets in which sovereign bonds are the only internationally-traded asset. We have obtained analytic results for a two-country endowment economy model, and then we have confirmed (using numerical methods) that a model with endogenous labor supply has qualitatively similar properties. In particular, when agents are very patient and shocks are not very persistent, we find that the welfare under incomplete markets is nearly as high as that under complete markets; in contrast, when agents are relatively impatient and shocks are highly persistent, the welfare level is similar to that of the autarkic economy. For realistic cases in which agents are very patient and shocks are highly persistent, the relative welfare of the incomplete-market economy is highly sensitive to the specific values of these parameters.

These findings suggest that the welfare implications of financial market incompleteness may vary substantially across different types of exogenous disturbances. For example, sovereign bonds may be reasonably effective in facilitating international risk-sharing in response to temporary shifts in a country's monetary or fiscal policy. On the other hand, sovereign bonds are probably not very useful in smoothing consumption in response to longer-term geopolitical or institutional changes. Unfortunately, moral hazard problems and other contractual difficulties severely limit the extent to which households in a particular country can insure themselves against such events. In practice, therefore, such shocks tend to generate highly persistent differences in living standards across countries.

In future work, we intend to extend our analysis in two directions. First, the framework of this paper can be used to obtain analytic results for cases in which the shocks have a persistent impact on the growth rate rather than the level of each

country's endowment. Second, we hope to extend the model to consider various types of bond market frictions, such as exogenous bounds on asset levels (cf. Huggett 1993; Levine and Zame 1999; Kubler and Schmedders 2000), endogenous solvency constraints (cf. Alvarez and Jermann 1999), and enforcement constraints (cf. Kehoe and Perri 2000). Such frictions will allow us to analyze a recursive model structure, where shocks occur at every period. 


\section{A. Appendix}

\section{A.1. The Welfare of the Endowment Economy}

First, we analyze the simplified model with neither spillovers nor growth $(\theta=$ $0, \mu=1)$; thus, $Y_{t}=y_{t}$. In this case, the second-order approximation of the home country's utility with respect to the deviation of the endowment from its deterministic steady-state $(\bar{Y})$ is given by

$$
\frac{C_{t}^{1-\gamma}-1}{1-\gamma} \approx \frac{\bar{Y}^{1-\gamma}-1}{1-\gamma}+\bar{Y}^{1-\gamma}\left[\left(\log \frac{C_{t}}{\bar{Y}}\right)+\frac{1-\gamma}{2}\left(\log \frac{C_{t}}{\bar{Y}}\right)^{2}\right]
$$

In order to derive $\log C_{t}$, we assume that the deterministic steady state of endowment is unity in both countries $\left(\bar{Y}=\bar{Y}^{*}=1\right)$ and that the initial asset level is zero $\left(A_{0}=0\right)$. Using $(2.12)$, we can log-approximate $C_{0}$ up to the second order:

$$
\begin{aligned}
\log C_{0} \approx & \left(1-\beta_{\rho}\right) \log Y_{0}+\beta_{\rho}\left(\frac{\log Y_{0}+\log Y_{0}^{*}}{2}\right) \\
& +\Theta\left(\log Y_{0}\right)^{2}+\Lambda\left(\log Y_{0}\right)\left(\log Y_{0}^{*}\right)+\Phi\left(\log Y_{0}^{*}\right)^{2}
\end{aligned}
$$

where

$$
\begin{aligned}
\Theta & =\frac{\beta_{\rho}}{8}\left(4-3 \beta_{\rho}-2 \gamma+2 \beta_{\rho} \gamma\right)-\frac{(1-\gamma)(1-\beta) \rho}{4\left(1-\beta \rho^{2}\right)} \beta_{\rho}, \\
\Lambda & =-\frac{1}{2} \beta_{\rho}+\frac{1}{4} \beta_{\rho}^{2}, \\
\Phi & =\frac{\beta_{\rho}}{8}\left(\beta_{\rho}+2 \gamma-2 \beta_{\rho} \gamma\right)+\frac{(1-\gamma)(1-\beta) \rho}{4\left(1-\beta \rho^{2}\right)} \beta_{\rho},
\end{aligned}
$$

and

$$
\beta_{\rho}=\frac{\beta(1-\rho)}{1-\beta \rho} .
$$

Using this expression together with stationary version of (2.13), we can approximate $\log C_{t}$ for all $t=1,2, \ldots$ Now we obtain the expected lifetime utility (denoted by $V$ ) of the incomplete-markets economy:

$$
\approx \sum_{t=0}^{\infty} \beta^{t} \mathrm{E}\left[\log C_{t}+\frac{1-\gamma}{2}\left(\log C_{t}\right)^{2}\right]
$$




$$
\begin{aligned}
& \approx \frac{E\left[\log Y_{0}\right]}{1-\beta \rho}+\sum_{t=0}^{\infty} \beta^{t}\left[\begin{array}{c}
\Theta+\frac{\rho^{2 t}-1}{8}+\frac{1-\gamma}{8}\left(\rho^{t}+1-\beta_{\rho}\right)^{2} \\
+\psi \Lambda-\psi \frac{\rho^{2 t}-1}{4}+\psi \frac{(1-\gamma)}{4}\left(\rho^{2 t}-(1-\beta)^{2}\right) \\
+\Phi+\frac{\rho^{2 t}-1}{8}+\frac{1-\gamma}{8}\left(\rho^{t}-1+\beta_{\rho}\right)^{2}
\end{array}\right] \sigma^{2} \\
& =-\left[\frac{1}{1-\beta \rho}-\frac{1}{1-\beta \rho^{2}}\left((1-\gamma)+\frac{(1-\psi) \beta \gamma}{2}\left(\frac{1-\rho}{1-\beta \rho}\right)^{2}\right)\right] \frac{\sigma^{2}}{2}
\end{aligned}
$$

Expected lifetime utility of autarky and the complete markets are given by

$$
\begin{aligned}
V^{\text {aut }} & \approx \sum_{t=0}^{\infty} \beta^{t} \mathrm{E}\left[\log Y_{t}+\frac{1-\gamma}{2}\left(\log Y_{t}\right)^{2}\right] \\
& \approx-\left[\frac{1}{1-\beta \rho}-\frac{1-\gamma}{1-\beta \rho^{2}}\right] \frac{\sigma^{2}}{2} \\
V^{\text {comp }} & \approx \sum_{t=0}^{\infty} \beta^{t} \mathrm{E}\left[\log \left(\frac{Y_{t}+Y_{t}^{*}}{2}\right)+\frac{1-\gamma}{2}\left(\log \left(\frac{Y_{t}+Y_{t}^{*}}{2}\right)\right)^{2}\right] \\
& \approx-\left[\frac{1}{1-\beta \rho}-\frac{1}{1-\beta \rho^{2}}\left(1-\frac{\gamma}{2}(1+\psi)\right)\right] \frac{\sigma^{2}}{2} .
\end{aligned}
$$

With non-zero spillovers, all derivations go through with $(\rho-\theta)$ replacing $\rho$. With non-zero growth in the endowments, the same first-order conditions hold using growth adjusted variables $\left(y_{t}\right.$ and $\left.c_{t}\right)$ and the growth adjusted discount factor $\tilde{\beta}=\beta \mu^{1-\gamma}$ in place of the discount factor $\beta$. In calculating welfare, however, we need to adjust for a constant term due to the presence of $\beta$ when adding instantaneous utilities across all time periods:

$$
\begin{aligned}
& V^{\text {inc }} \text { (with growth) } \\
\approx & \sum_{t=0}^{\infty} \beta^{t} \mathrm{E}\left[\log C_{t}+\frac{1-\gamma}{2}\left(\log C_{t}\right)^{2}\right] \\
= & \sum_{t=0}^{\infty} \tilde{\beta}^{t} \mathrm{E}\left[\log c_{t}+\frac{1-\gamma}{2}\left(\log c_{t}\right)^{2}\right]+\Delta \\
= & -\left[\frac{1}{1-\tilde{\beta} \rho}-\frac{1}{1-\tilde{\beta} \rho^{2}}\left((1-\gamma)+\frac{(1-\psi) \tilde{\beta} \gamma}{2}\left(\frac{1-\rho}{1-\tilde{\beta} \rho}\right)^{2}\right)\right] \frac{\sigma^{2}}{2}+\Delta(\text { A. } 6)
\end{aligned}
$$

where

$$
\Delta=\frac{1}{1-\gamma}\left(\frac{\tilde{\beta}}{1-\tilde{\beta}}-\frac{\beta}{1-\beta}\right)
$$


The value of $\Delta$ is equal to steady-state expected lifetime utility, that is, the level of lifetime utility attained when each household's consumption is given by its steady-state endowment path. Similarly, the expected utility of autarky and the complete markets with growth can be expressed by equations (A.4) and (A.5) with $\tilde{\beta}$ replacing $\beta$ and with the same constant term. Using compensating variations, we can express deviations of expected lifetime utility $(V)$ in terms of the corresponding deviation in certainty-equivalent consumption in the initial period relative to steady state (denoted by $W$ in the main text).

\section{A.2. The Finite-Horizon Economy}

The model with logarithmic instantaneous utility and with a finite horizon of $J$ periods can be solved by substituting the gross interest rate (given by equation 2.10 ) into the $J$-period version of the intertemporal budget constraint (2.5). For simplicity, we assume the economy has no growth. Then consumption and asset holdings at time $t$ can be expressed as:

$$
\begin{aligned}
C_{t} & =\beta_{J}\left(\frac{Y_{t}+Y_{t}^{*}}{2}\right)+\left(1-\beta_{J}\right)\left(Y_{t}+A_{t}\right), \\
A_{t+1} & =\frac{\beta_{J}}{\beta} \frac{2 \bar{Y}}{Y_{t}+Y_{t}^{*}}\left(A_{t}+\frac{Y_{t}-Y_{t}^{*}}{2}\right)
\end{aligned}
$$

where

$$
\beta_{J}=\beta \frac{1-\beta^{J+1}}{1-\beta^{J+2}}
$$

Note that $\beta_{J}$ is increasing in both $\beta$ and $J$ and that $\left(\frac{\beta_{J}}{\beta}\right)$ is decreasing in $\beta$.

Assuming $A_{0}=0$, the welfare of the incomplete-markets economy is given by

$$
\begin{aligned}
V^{\text {inc }} & =\sum_{t=0}^{\infty} \beta^{t} \mathrm{E}\left(\log C_{t}\right) \\
& \approx \frac{1-\beta^{J+2}}{1-\beta} \mathrm{E}\left(\log C_{0}\right)-\frac{\beta\left(1-\beta^{J+1}\right)}{1-\beta} \mathrm{E}\left(\log \frac{Y_{0}+Y_{0}^{*}}{2}\right) \\
& \approx \frac{1-\beta^{J+2}}{1-\beta} \beta_{J}\left(2-\beta_{J}\right) \frac{\sigma^{2}}{4}-\frac{\beta\left(1-\beta^{J+1}\right)}{1-\beta} \frac{\sigma^{2}}{4} \\
& \approx \beta_{J} \frac{\sigma^{2}}{4} \approx \beta_{J} V^{\text {comp }} .
\end{aligned}
$$

Since $V^{\text {aut }}=0$, it is evident that $\lambda^{c}=\beta_{J}$. 


\section{A.3. The Solution Algorithm for the Production Economy with Labor}

The Lagrangian of this problem is

$$
\sum_{t=0}^{\infty}\left[\beta^{t}\left(\frac{C_{t}^{1-\gamma}-1}{1-\gamma}+\nu_{0} \nu\left(1-L_{t}^{\frac{1}{\nu}}\right)\right)+\beta^{t} \lambda_{t}\left(R_{t-1} B_{t-1}+X_{t} L_{t}^{1-\alpha}-C_{t}-B_{t}\right)\right]
$$

Assuming $\nu_{0}=1-\alpha$ for notational simplicity, we get the first order conditions at time $t$ :

$$
\begin{aligned}
C_{t} & :{ }_{t}^{-\gamma}=\lambda_{t}, \\
L_{t} & : \quad L_{t}^{\frac{1}{\nu}-1}=X_{t} L_{t}^{-\alpha} \lambda_{t}, \\
B_{t}: & \lambda_{t}=\beta R_{t} \mathrm{E}_{t} \lambda_{t+1} .
\end{aligned}
$$

Combining labor supply equation with the budget constraint, we have

$$
C_{t}+B_{t}=R_{t-1} B_{t-1}+X_{t}^{\frac{1}{1-(1-\alpha) \nu}} C_{t}^{\frac{-(1-\alpha) \nu \gamma}{1-(1-\alpha) \nu}} .
$$

Combining the first-order conditions of the foreign country and the bond market clearing condition, the economy is expressed by the following five equations:

$$
\begin{aligned}
\frac{1}{C_{t}^{\gamma}} & =\beta R_{t} \mathrm{E}_{t} \frac{1}{C_{t+1}^{\gamma}}, \\
\frac{1}{\left(C_{t}^{*}\right)^{\gamma}} & =\beta R_{t} \mathrm{E}_{t} \frac{1}{\left(C_{t+1}^{*}\right)^{\gamma}}, \\
C_{t}+B_{t} & =R_{t-1} B_{t-1}+X_{t}^{\frac{1}{1-(1-\alpha) \nu}} C_{t}^{\frac{-(1-\alpha) \nu \gamma}{1-(1-\alpha) \nu}}, \\
C_{t}^{*}+B_{t}^{*} & =R_{t-1} B_{t-1}^{*}+\left(X_{t}^{*}\right)^{\frac{1}{1-(1-\alpha) \nu}}\left(C_{t}^{*}\right)^{\frac{-(1-\alpha) \nu \gamma}{1-(1-\alpha) \nu}}, \\
B_{t}+B_{t}^{*} & =0 .
\end{aligned}
$$

Henceforth we use $Z_{t}$ to indicate the relevant vector of endogenous variables:

$$
Z_{t}=\left(C_{t}, C_{t}^{*}, B_{t}, B_{t}^{*}, R_{t}\right)^{\prime}
$$

Suppose that we are interested in calculating the solution for $M$ periods, say between $\tau$ and $\tau+M-1$. For a given choice $M$ of the time horizon, we solve for the $5 * M$ unknowns $\left\{Z_{\tau+j}, j=0,1, \ldots, M-1\right\}$. The system of $5 * M$ equations includes the first two Euler equations listed above over $(M-1)$ periods for $t=$ 
$\tau, \tau+1, \ldots, \tau+M-2$, and the remaining three equations over $M$ periods for $t=\tau, \tau+1, \ldots, \tau+M-1$. The final two equations in the system are obtained by assuming that the economy has reached its new steady state by the final period $(\tau+M-1)$. The assumption that consumption reaches a steady state pins down the interest rate at the final period based on the Euler equation,

$$
R_{\tau+M-1}=\beta^{-1} .
$$

Using the assumption that variables are constant from final period $(\tau+M-1)$ and onwards, we rewrite the budget constraint at $(\tau+M)$ as follows:

$$
C_{\tau+M-1}=\left(R_{\tau+M-1}-1\right) B_{\tau+M-1}+Y_{\tau+M-1} .
$$

The appropriate value of the time horizon can be determined using an iterative approach. In particular, starting from an initial guess $M^{(0)}$, solve for

$$
Z^{(0)}=\left\{Z_{\tau+j}^{(0)}, j=0,1, \ldots, M^{(0)}-1\right\}
$$

using the solution method described above. Next, choose a longer horizon $M^{(1)}>$ $M^{(0)}$ and solve for

$$
Z^{(1)}=\left\{Z_{\tau+j}^{(1)}, j=0,1, \ldots, M^{(1)}-1\right\} .
$$

If the longer horizon has an arbitrarily small effect on the solution path (that is, $\left|Z_{\tau+j}^{(1)}-Z_{\tau+j}^{(0)}\right|$ is small enough for all $\left.j=0,1, \ldots, M^{(0)}-1\right)$, then $M^{(0)}$ is a satisfactory choice for the time horizon. Otherwise, repeat these steps using higher values of the time horizon until some $M^{(k)}$ is found which satisfies the convergence criterion. 


\section{References}

[1] Alvarez, F. and Jermann, U., 1999, Quantitative Asset Pricing Implications of Endogenous Solvency Constraints, NBER Working Paper No. 6953.

[2] Backus, D., P. Kehoe, and F. Kydland, 1992, International Real Business Cycles, Journal of Political Economy 100, 745-775.

[3] Barro, R., and X. Sala-i-Martin, 1995, Economic Growth, New York: McGraw-Hill.

[4] Baxter M. and M. Crucini, 1993, Explaining Saving-Investment Correlation, American Economic Review 83, 416-436.

[5] Baxter, M. and M. Crucini, 1995, Business Cycles and Asset Structure of Foreign Trade, International Economic Review 36, 821-54.

[6] Baxter, M., 1997, International Trade and Business Cycles, in: G.H. Grossman and K. Rogoff, eds., Handbook of international economics, Vol. 3 (NorthHolland, Amsterdam).

[7] Cole, H., 1988, Financial Structure and International Trade, International Economic Review 29, 237-259.

[8] Davis, S., J. Nalewaik and P. Willen, 2000, On the Gains to International Trade in Risky Financial Asset, mimeo.

[9] Devereux, M. and M. Saito, 1997, Growth and Risk-sharing with Incomplete Assets Markets, Journal of International Economics 42, 453-481.

[10] Fair R. and J. Taylor, 1983, Solution and Maximum Likelihood Estimation of Dynamic Nonlinear Rational Expectations Models, Econometrica 51, 116985.

[11] Friedman, M., 1957, A Study of Consumption Function, Princeton University Press.

[12] Glick, R. and K. Rogoff, 1995, Global versus Country-specific Productivity Shocks and the Current Account, Journal of Monetary Economics 35, 159192. 
[13] Huggett, M., 1993, The Risk Free Rate in Heterogeneous-agents, Incomplete Insurance Economies, Journal of Economic Dynamics and Control 17, 953969.

[14] Kehoe, P. and Perri, F., 2000, International Business Cycles with Endogenous Incomplete Markets, FRB Minneapolis Staff Report No. 265.

[15] Kim, S.H., 1997, International Business Cycles in a Partial-Risk-Sharing Market with Capital Income Taxation, chapter 3 in Ph.D. Dissertation, Yale University.

[16] Kim, J. and S.H. Kim, 1999, Spurious Welfare Reversals in International Business Cycle Models, mimeo.

[17] Kollmann R., 1996, Incomplete Asset Markets and the Cross-Country Consumption Correlation Puzzle, Journal of Economic Dynamics and Control 20, 945-961.

[18] Kollmann R., 1998, US Trade Balance Dynamics: the Role of Fiscal Policy and Productivity Shocks, Journal of International Money and Finance 17, 637-669.

[19] Kubler, F. and K. Schmedders, 2000, Incomplete Markets, Transitory Shocks, and Welfare. mimeo.

[20] Levine, D. and W. Zame, 1999, Does Market Incompleteness Matter?, mimeo.

[21] Lewis, K., 2000, Why do Stocks and Consumption Imply Such Different Gains from International Risk-Sharing?, Journal of International Economics $52,1-35$.

[22] Lucas, R.E., Jr., 1987, Models of Business Cycles, Cambridge, MA: Blackwell.

[23] Mendoza, E., 1995, The Terms of Trade, the Real Exchange Rate and Economic Fluctuations, International Economic Review 36, 101-137.

[24] Mendoza, E. and L. Tesar, 1998, The International Ramifications of Tax Reforms: Supply-Side Economics in a Global Economy, American Economic Review 88, 226-245. 
[25] Mendoza, E. and M. Uribe, 1999, The Business Cycles of Balance-of Payment Crises: A Revision of Mundellan Framework, NBER Working Paper No. 7045 .

[26] Obstfeld, M. and K. Rogoff, 1996, Foundations of International Macroeconomics, MIT Press.

[27] Romer, D., 1996, Advanced Macroeconomics, New York: McGraw-Hill.

[28] Sims, C., 2000, Second Order Accurate Solution of Discrete Time Dynamic Equilibrium Models, mimeo.

[29] Tesar, L., 1995, Evaluating the Gains from International Risksharing, Carnegie-Rochester Conference Series on Public Policy 42, 95-143.

[30] van Wincoop, E., 1999, How Big are Potential Gains from International Risksharing?, Journal of International Economics 47, 109-35.

[31] Willen, P., 1999, Welfare, Financial Innovation and Self Insurance in Dynamic Incomplete Market Models, mimeo.

[32] Woodford, M., 1999, Inflation Stabilization and Welfare, mimeo. 


\section{Page 25}

Figure 1. Welfare Gains over Autarky

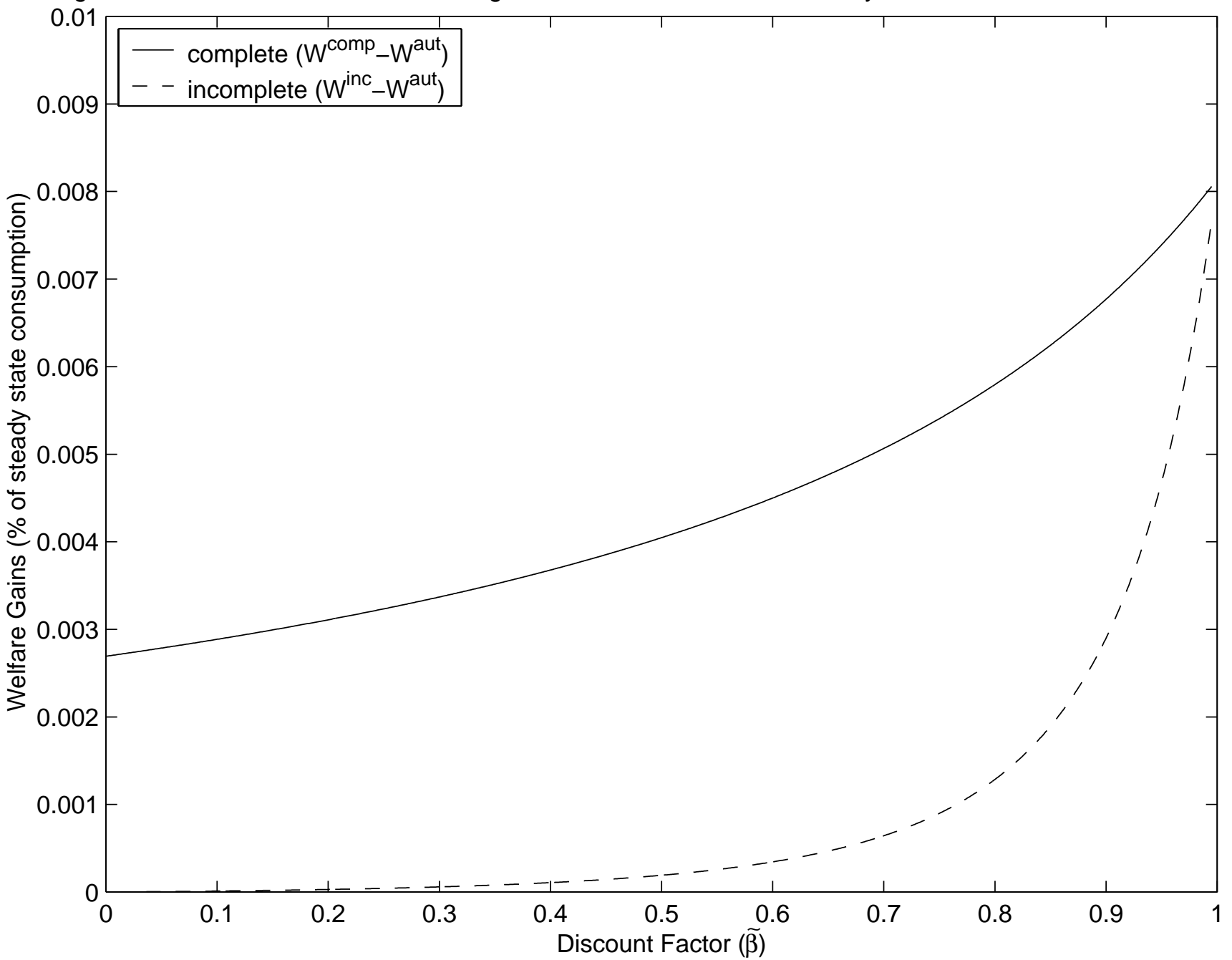


Figure 2. Welfare Gains over Autarky

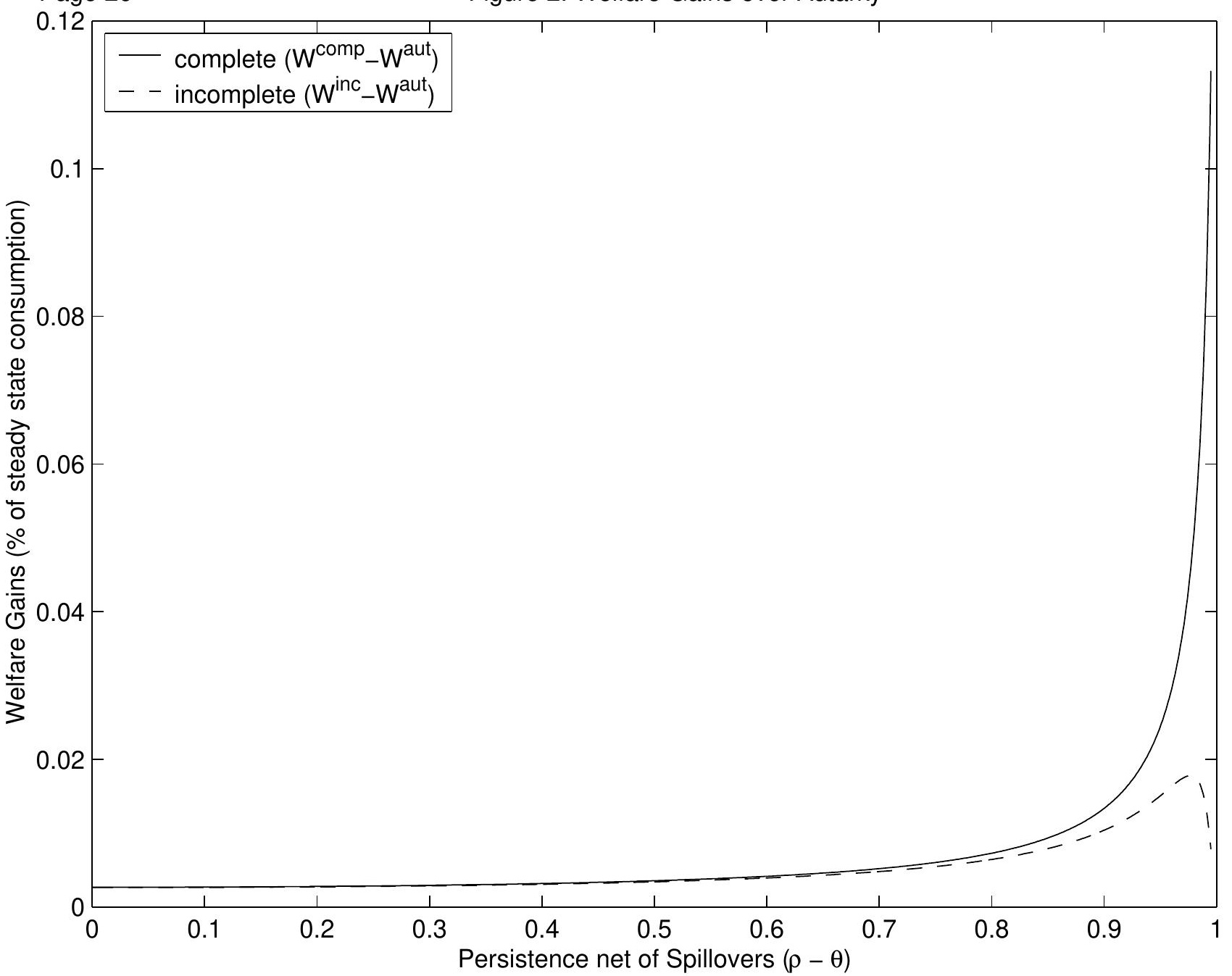


Figure 3. Relative Welfare Index of Incomplete Markets

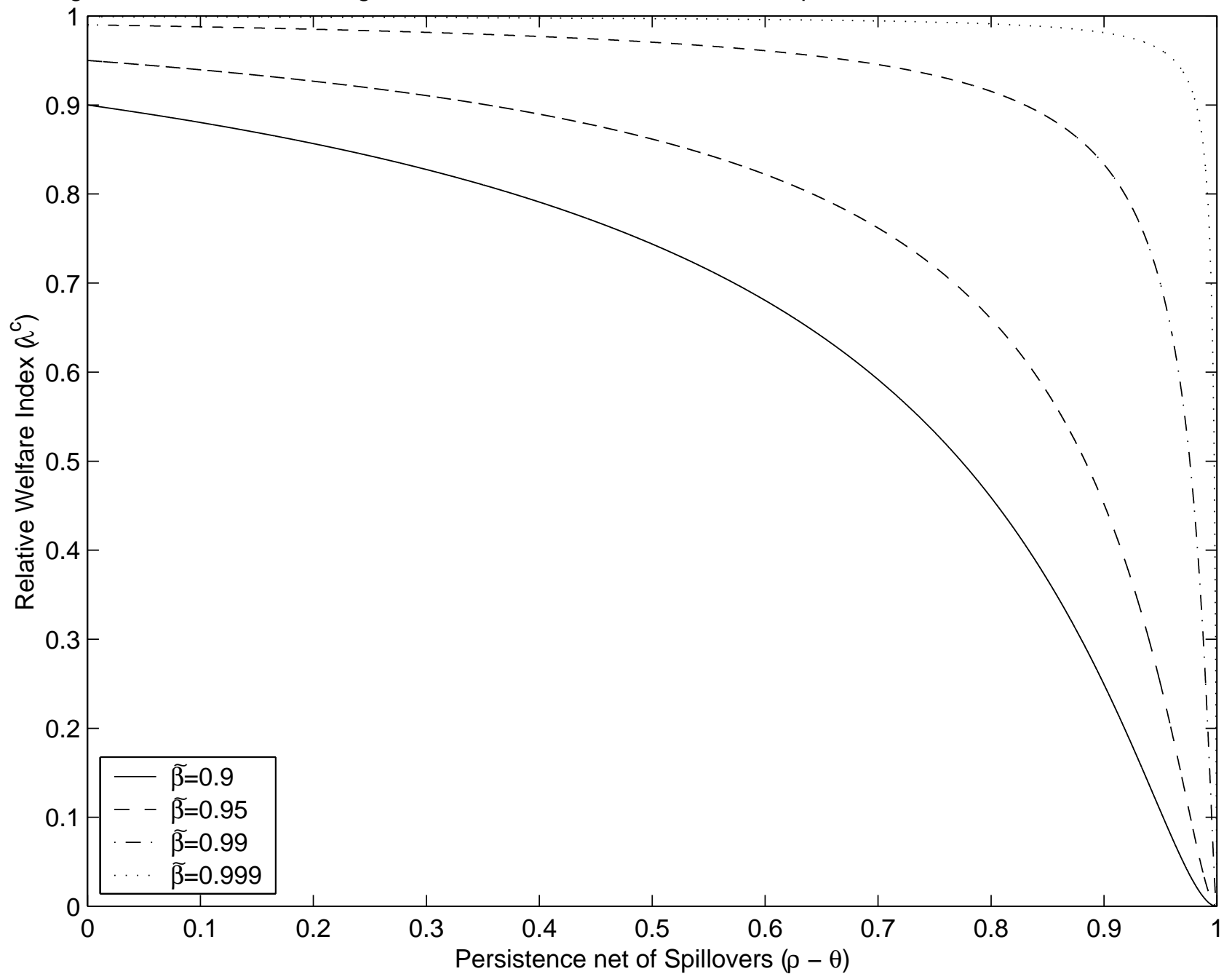


Figure 4. Welfare Gains over Autarky (Production Economy with Labor)

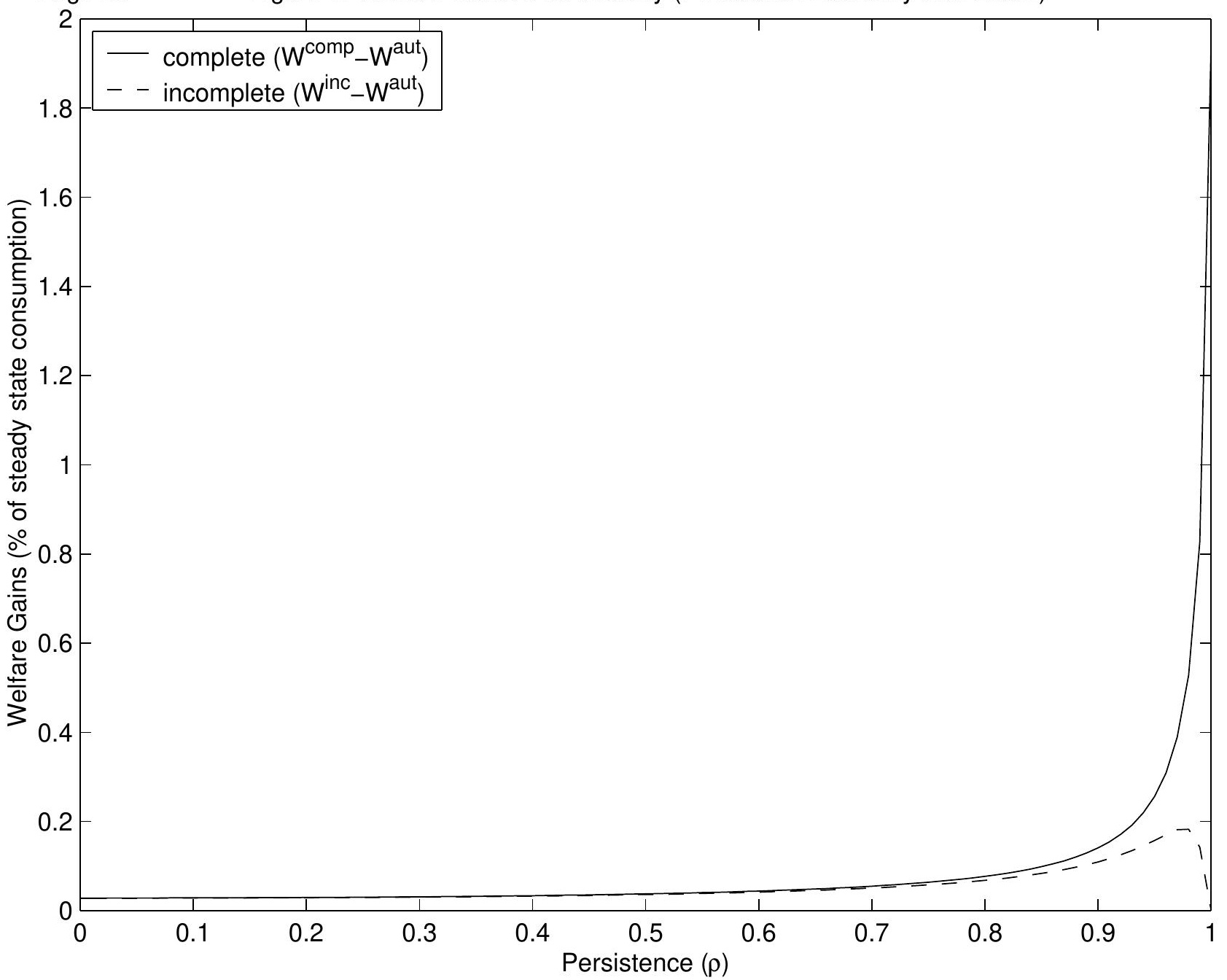

